\title{
Rações comerciais e o rendimento de carcaça e subprodutos de rã-touro ${ }^{1}$
}

\author{
Commercial food and the carcass yield and by-products of bullfrog
}

\section{Alex Poeta Casali ${ }^{2}$ Onofre Maurício de Moura ${ }^{3}$ Samuel Lopes Lima ${ }^{4}$}

\section{RESUMO}

Objetivou-se avaliar o efeito do sexo e do uso de quatro rações comerciais extrusadas (R1, R2, R3 e R4) e uma ração peletizada ( $R 5)$ sobre o rendimento de carcaça $e$ aproveitamento de subprodutos da ranicultura, após 56 dias de experimentação. As rações comerciais eram recomendadas para diferentes espécies e fases de desenvolvimento animal, a saber: $R 1$ = para rãs (na fase inicial, imagos); $R 2$ = para peixes onívoros (em fase inicial); $R 3$ = para trutas (peixe carnívoro na fase de crescimento); e R4 = para trutas (na fase inicial). Foram analisados os teores (\%) de matéria seca (MS), proteína bruta $(P B)$, extrato etéreo (EE), fibra bruta $(F B)$ e matéria mineral (MM) das rações. Foram utilizadas 80 rãs-touro com peso médio inicial de $51,57 \mathrm{~g}$ distribuídas em um delineamento em blocos casualizados em esquema fatorial (cinco rações $X$ dois sexos) com oito repetições de uma rã por unidade experimental. Não houve significância na interação entre os fatores para todas as variáveis analisadas. Os menores valores de rendimento de carcaça foram observados nos animais que receberam a ração $R 3$, sendo as demais iguais. No aproveitamento de subprodutos, destacou-se a ração $R 1$, que proporcionou maior peso de fígado e descartes, e a ração $R 4$, com maior peso de fígado e corpo gorduroso. O sexo dos animais apenas influenciou no aproveitamento de descartes, sendo que os machos proporcionaram maiores médias.

Palavras-chave: características alométricas, ração, Rana catesbeiana, ranicultura.

\section{ABSTRACT}

The objective was to evaluate the effect of the sex and the use of four commercial extruded foods (R1, R2, R3, and R4) and a pelleted food (R5) on the carcass yield and the byproduct utilization of the bullfrog culture, after 56 days of experimentation. The commercial foods were recommended to different species or phases of growth: $R 1=$ for frogs in the initial phase; $R 2$ = for omnivorous fish in the initial phase; $R 3=$ for trout (carnivorous fish) in phase of growth; and R4 = for trout in initial phase. The chemical composition (DM, CP, EE, CF and MM) was analyzed. Eighty bullfrogs with initial weight average of $51.57 \mathrm{~g}$ were distributed in a completely randomized blocks design in factorial scheme (five foods $X$ two sexes) with eight replicates of one animal for experimental unit. There was no significant interaction among the factors for all analyzed parameters. The lowest carcass yield was observed in animals fed with $R 3$ food, and the others had the same. In the by-product exploitation, the R1 food provided the greater weight of liver and discarding, and R4 food, provided bigger weight of liver and fat body. The sex of the animal was only influenced in the exploitation of discarding, and the males had provided greater averages.

Key words: alometrics indexes, food, frog culture, Rana catesbeiana.

\section{INTRODUÇÃO}

A criação de rãs em cativeiro vem cada vez mais se firmando como uma atividade viável e de grande potencial. Isto se deve, entre outros fatores, à qualidade nutricional da carne de rãs, que possui um adequado balanceamento de aminoácidos e baixo nível de gordura e colesterol, o que se apresenta como uma importante ferramenta de publicidade.

Os principais produtos da rã-touro explorados comercialmente são a carne e o couro, segundo LIMA \& AGOSTINHO (1988) que também mencionaram as potencialidades de aproveitamento

${ }^{1}$ Parte da dissertação de mestrado do primeiro autor junto a Universidade Federal da Paraíba (UFPB). Casali, bolsista Desenvolvimento Científico Regional e do Conselho Nacional de Desenvolvimento Científico e Tecnológico (CNPq). Lima bolsista do CNPq. ${ }^{2}$ UFPB, Bosque Acamari, 26, 36570-000, Viçosa, MG, Brasil. E-mail: apcparaiba@yahoo.com.br. Autor para correspondência. ${ }^{3}$ Departamento de Tecnologia Rural, Centro de Formação de Tecnólogos, UFPB, Bananeiras, PB, Brasil. E-mail: moura321@zaz.com.br

${ }^{4}$ UFPB, Bananeiras, PB, Brasil. E.mail: samuel@ufv.br 
de ovário (caviar) e fígado (patê). O aproveitamento do fígado de rã na fabricação de patê foi também reportado por SILVA \& OLIVEIRA (1994) e RODRIGUES et al. (1994), mas conforme menciona LIMA \& AGOSTINHO (1988), o maior problema da comercialização desses subprodutos seria a baixa produção. Em estudos mais recentes sobre a cadeia produtiva da ranicultura, LIMA et al. (1999) constataram que o aproveitamento de subprodutos da rã-touro ainda é inexpressivo, sendo fracamente representado pelo aproveitamento de pele e corpo gorduroso, prevalecendo ainda a comercialização dos produtos principais, carcaças inteiras e coxas.

O estudo da pele de rã e de seu aproveitamento pela indústria foi objeto de diversas pesquisas que relataram seu uso em cintos, bolsas, luvas, sapatos, fabrico de colas e tratamentos de queimaduras (SILVA \& OLIVEIRA, 1994; SILVA, 1995; LIMA et al., 1999; RAMOS, 2000). O aproveitamento do corpo gorduroso, na forma de óleo, foi relatado para uso na elaboração de cosméticos por SILVA \& OLIVEIRA (1994), SILVA (1995) e LIMA et al. (1999) que ainda reportaram seu uso como medicamento natural. Já as substâncias encontradas no oviduto também podem ser aproveitadas, apresentando propriedades de interesse com alto valor protéico e poder espessante (RAMOS, 2000). O aproveitamento de rejeitos (vísceras e outros), fora da unidade de abate, após processamento por terceiros, foi relatado por LIMA et al. (1999). AZEVEDO (1984) descreve a composição química da farinha de vísceras de rã mostrando que a mesma tem potencial para utilização como ingrediente de rações.

Estudos sobre características alométricas de rãs-touro foram feitos por RAMOS et al. (1998), que verificaram, em experimentos preliminares, que os rendimentos de carcaça e de músculo variavam de acordo com o desenvolvimento e o sexo do animal, confirmado posteriormente pelos resultados obtidos em RAMOS (2000).

O papel do alimento no desenvolvimento animal foi ressaltado por JUDGE et al. (1989), que relataram a possibilidade de controlar o crescimento de um tecido ou partes do corpo de interesse, através de um plano nutricional no momento adequado. Estas observações parecem ser reforçadas por FAUCONNEAU et al. (1995), que declararam que o desenvolvimento de tecidos com deposição de gordura é estimulado, durante o crescimento de carpas, mediante uso de lipídeos enriquecidos ou dietas artificiais com alto teor de energia.

Atualmente, usam-se rações comerciais extrusadas, formuladas para peixes carnívoros ou onívoros, em praticamente todos os criatórios. A reduzida tonelagem no consumo de alimento tem afastado o interesse das indústrias em desenvolverem e oferecerem, ao mercado, rações específicas e adequadas para esse anfíbio. Contudo, é possível encontrar ração rotulada para essa espécie, sem se ter informações de sua eficiência. Nenhuma publicação é encontrada, no Brasil, avaliando rações comerciais disponíveis, que são a alternativa mais usada dos produtores que, geralmente, têm poucas informações e muitas dificuldades em fazer uma ração artesanal.

Objetivou-se com a execução desse trabalho avaliar o efeito do sexo e do uso de quatro rações comercias (extrusadas) e uma ração artesanal (peletizada) sobre o rendimento de carcaça e aproveitamento de subprodutos de rãs-touro.

\section{MATERIAL E MÉTODOS}

O experimento foi conduzido no Setor de Ranicultura do Centro de Formação de Tecnólogos da UFPB - Campus de Bananeiras. Para iniciar o experimento 400 rãs foram alojadas em 40 mini-baias (caixas plásticas de $55.000 \mathrm{~cm}^{3}$ cada), com piso de fibra de vidro, instaladas em uma sala de experimentação. Cada mini-baia possuía abrigo, cocho e piscina, capaz de abrigar uma densidade inicial de 10 rãs (50 animais por $\mathrm{m}^{2}$ ) e fornecer $17,5 \mathrm{~cm}^{2}$ de área de cocho e $1,2 \mathrm{~L}$ de água (da piscina) por rã. As mini-baias obedeceram, em escala reduzida, as proporções do Sistema Anfigranja, preconizado por LIMA \& AGOSTINHO (1992).

As temperaturas do ambiente experimental, de máxima e mínima, foram respectivamente de $31,0^{\circ} \mathrm{C}$ e $21,5^{\circ} \mathrm{C}$, a média das mínimas foi de $22,8^{\circ} \mathrm{C}$, a média das máximas foi de $29,2^{\circ} \mathrm{C}$, e a média geral de $26,0^{\circ} \mathrm{C}$. As temperaturas médias da água da piscina tiveram o maior valor observado de $27,5^{\circ} \mathrm{C}$ e o menor de $22,0^{\circ} \mathrm{C}$, a média das manhãs foi de $22,9^{\circ} \mathrm{C}$, a média das tardes foi de $26,6^{\circ} \mathrm{C}$, e a média geral de $24,7^{\circ} \mathrm{C}$.

Foram testadas cinco rações, sendo quatro rações comerciais do tipo extrusada (R1, R2, R3 e R4) recomendadas para diferentes espécies e fases de desenvolvimento animal, a saber: R1 = para rãs (na fase inicial, imagos); R2 = para peixes onívoros (em fase inicial); R3 = para trutas (peixe carnívoro na fase de crescimento); e R4 = para trutas (na fase inicial).

Os ingredientes utilizados na elaboração da ração peletizada (R5) foram doados pela empresa Guaraves, localizada na cidade de Guarabira-PB (Tabela 1). Os níveis nutricionais utilizados na formulação da ração peletizada foram obtidos de valores médios das margens de segurança oferecida 
Tabela 1 - Ingredientes utilizados na elaboração da ração peletizada e suas respectivas porcentagens.

\begin{tabular}{ll}
\hline Ingrediente & Quantidade (\%) \\
\hline Soja integral extrusada & 37,6 \\
Farinha de vísceras de frango & 20,0 \\
Farinha de carne & 15,0 \\
Farelo de trigo & 11,7 \\
Proteinoso (far. Glútem 60 ou glutenose) & 10,0 \\
Quirera de arroz $_{\text {Sal }}$ & 4,0 \\
Calcário $^{2}$ & 1,2 \\
Premix mineral $^{2}$ & 0,2 \\
Premix vitamínico $^{1}$ & 0,1 \\
B H T (antioxidante) & 0,1 \\
Total $^{2}$ & 0,1 \\
\hline
\end{tabular}

${ }^{1}$ Rovimix matrizes, ${ }^{2}$ Roligomix mineral.

como níveis de garantia das rações comerciais extrusadas. Essa medida foi tomada devido à falta de dados conclusivos sobre exigências de rãs e para permitir uma semelhança nutricional validando as comparações dos efeitos das rações sobre o desempenho das rãs. A peletização da ração foi feita numa prensa peletizadora com matriz de $5 \mathrm{~mm}$. Para reduzir o efeito do tamanho do pelete nos resultados, a ração peletizada foi triturada em um triturador de grãos, depois peneirada, a fim de que fossem obtidas partículas de 1 a $4 \mathrm{~mm}$.

As rações foram analisadas no Laboratório de Controle de Qualidade de Alimentos do Centro de Formação de Tecnólogos da UFPB, conforme SILVA (1981). Foram analisadas matéria seca (MS), proteína bruta $(\mathrm{PB})$, extrato etéreo (EE), fibra bruta (FB), matéria mineral (MM) e energia bruta (EB). O tamanho de pelete foi determinado com ajuda de um paquímetro. Os resultados das análises físicoquímicas e energéticas das rações são apresentados na tabela 2.

A ração para trutas em crescimento (R3) foi a única que apresentou, em sua composição (níveis de garantia), a presença de antibiótico como promotor de crescimento. A implicação do uso de tal componente e suas dosagens não foram estudadas neste trabalho, sendo que suas conseqüências no desempenho animal ou em caso de toxicidade, só poderão ser elucidadas em um trabalho específico para tal.

Como atrativo alimentar, utilizaram-se larvas de mosca (Musca doméstica), que movimentavam as rações, em proporção fixa de $10 \%$ (em peso) do alimento fornecido. As rãs foram alimentadas apenas uma vez ao dia em regime "ad libitum", quando era feita a limpeza da baia e troca de água da piscina.
Tabela 2 - Tamanho dos peletes e composição centesimal e energética das rações experimentais

\begin{tabular}{|c|c|c|c|c|c|}
\hline \multirow{2}{*}{ Composição } & \multicolumn{5}{|c|}{ Rações $^{1}$} \\
\hline & $\mathrm{R} 1$ & $\mathrm{R} 2$ & R3 & R4 & R5 \\
\hline $\begin{array}{ll}\text { Tamanho } & \text { dos } \\
\text { Peletes (mm) } & \end{array}$ & 4,24 & 3,57 & 4,09 & 3,88 & 3,26 \\
\hline Matéria Seca (\%) & 92,45 & 92,51 & 95,40 & 95,92 & 95,25 \\
\hline Proteína Bruta (\%) & 47,13 & 38,24 & 47,73 & 46,94 & 46,36 \\
\hline Extrato Etéreo (\%) & 5,11 & 2,72 & 9,40 & 10,51 & 12,21 \\
\hline Fibra Bruta (\%) & 1,81 & 4,55 & 1,22 & 2,08 & 3,01 \\
\hline $\begin{array}{l}\text { Matéria Mineral } \\
(\%)\end{array}$ & 9,83 & 8,27 & 12,00 & 8,44 & 12,77 \\
\hline EB (kcal/Kg) & 4522 & 4298 & 4630 & 4807 & 4727 \\
\hline
\end{tabular}

${ }^{1} \mathrm{R} 1=$ rãs na fase inicial; R2 = peixes onívoros na fase inicial; R3 $=$ trutas na fase de crescimento; R4 = trutas na fase inicial; e R5 = peletizada.

Para o cálculo das características alométricas, foram utilizadas medidas denominadas “medidas básicas”, como se segue: Peso de carcaça, peso de gônadas, peso de fígado, peso de corpo gorduroso, peso de pele e peso de descartes. As medidas básicas foram relacionadas com o peso vivo (peso corporal) dos animais, resultando em composições (rendimento de carcaça, índices e relações) cujas fórmulas de obtenção são relacionadas

a seguir: a ) Rendimento de carcaça: $R c=\frac{W c}{W t} \times 100$

Onde, $\mathrm{Wc}=$ Peso da carcaça $(\mathrm{g})$ e $\mathrm{Wt}=$ Peso vivo (g); b ) Índice gonadossomático (testículos no macho, e ovário mais oviduto nas fêmeas): $I G S=\frac{W g}{W t} \times 100$ Onde, Wg = Peso das gônadas (g); c) Índice hepatossomático: $I H S=\frac{W h}{W t} \times 100$ Onde, $\mathrm{Wh}=$ Peso do fígado (g); d) Índice Lipossomático : $I L S=\frac{W l}{W t} \times 100 \quad$ Onde, $\mathrm{Wl}=$ Peso do corpo gorduroso (g); e) Relação pele/peso corporal: $R(W p / W t)=\frac{W p}{W t} \times 100 \quad$ Onde, $\mathrm{Wp}=$ Peso da pele (g); e f) Relação descartes/peso corporal: [peso de vísceras (órgãos remanescentes da evisceração como aparelho respiratório, coração, tubo digestivo e rins) a cabeça com pele, as patas com pele, o corte de cloaca, aparas da toalete, e líquidos corporais (urina e sangue) sendo que o peso, desses três últimos, foi

Ciência Rural, v. 35, n. 5, set-out, 2005. 
obtido por diferença do peso vivo de cada animal].

$$
R(W d / W t)=\frac{W d}{W t} \times 100 \quad \text { Onde, } \mathrm{Wd}=\text { Peso dos }
$$

descartes (g).

$\mathrm{O}$ experimento foi instalado em esquema fatorial $5 \times 2$ (cinco rações $\mathrm{X}$ dois sexos) com oito repetições, em um delineamento em blocos casualizados. Os blocos foram constituídos pelo peso inicial dos animais, a fim de que esse parâmetro fosse isolado. O peso inicial de cada bloco foi: Bloco $1=$ 41,99 \pm 2,96g; Bloco $2=44,76 \pm 0,76 g$; Bloco $3=$ $46,70 \pm 1,97 \mathrm{~g}$; Bloco $4=50,15 \pm 0,95 \mathrm{~g}$; Bloco $5=$ $52,79 \pm 1,01 \mathrm{~g}$; Bloco $6=55,49 \pm 0,97 \mathrm{~g}$; Bloco $7=$ 58,19 \pm 1,23g; e Bloco $8=62,50 \pm 2,53$.

Ao final de 56 dias de fornecimento das rações, foi colhido de forma aleatória, um animal de cada sexo por mini-baia, totalizando 80 animais (parcelas), que passaram por um jejum de 48 horas, sendo posteriormente pesados, insensibilizados por eletronarcose com $60 \mathrm{~V}$ e $350 \mathrm{~mA}$ por 7 segundos (MOURA, 2000) e abatidos, pesando-se a carcaça e demais órgãos/tecidos, para os cálculos alométricos. Em todas as pesagens, foi utilizada uma balança eletrônica digital com precisão de $0,001 \mathrm{~g}$.

Todos os dados foram submetidos à análise de variância e, quando necessário, foi aplicado o teste Student Newman-Keuls, para comparação de médias, ao nível de 5\% de probabilidade, pelo programa SAEG (8.0).

\section{RESULTADOS E DISCUSSÃO}

As análises de variância relativas ao estudo do efeito de sexo e rações sobre o rendimento de carcaça, as relações e os índices alométricos podem ser observados na tabela 3 . Verificou-se que não houve significância $(\mathrm{P}>0,05)$ para a interação (rações $\mathrm{X}$ sexo), em nenhuma variável estudada, assim avaliaramse os fatores rações e sexo de forma independente.

A ração R1 proporcionou um maior peso de carcaça $(\mathrm{P}<0,05)(\mathrm{Wc})$, em relação às demais, enquanto que a ração para R3 proporcionou o menor Wc (Tabela 3). Não foi encontrada diferença significativa $(\mathrm{P}>0,05)$ para Wc entre machos e fêmeas, sendo o peso médio dos machos de 106,64g e das fêmeas de 101,78 g. Como a carcaça é a forma mais representativa de comercialização de produtos da ranicultura, a ração R1 é a mais recomendada, por conferir maior Wc, independente do sexo a ser criado.

Os valores de rendimento de carcaça (Rc) foram influenciados significativamente $(\mathrm{P}<0,05)$ pelas diferentes rações onde se observaram maiores valores de Rc nas rãs alimentadas com R1, R2 e R5, em relação a R3, tendo a R4 proporcionado um Rc intermediário (Tabela 3). O sexo da rã não afetou $(\mathrm{P}>0,05)$ os valores médios de Rc dos machos e das fêmeas.

Testando níveis diferentes de PB na ração, BARBALHO (1991) encontrou, em média, 58,84\% de Rc, com animais de 62,6 a 115,9g de peso vivo ao abate, sem diferenciar o sexo das rãs e com idade aproximadamente de 134 dias de recria. Provavelmente o maior Rc encontrado por esse autor, foi em função do menor peso das rãs ao abate. Já RAMOS (2000) encontrou médias de 54,2\% de Rc para machos e 48,3\% para fêmeas, aos 269 dias de recria, quando as rãs estavam com 189,6g de peso vivo. O menor Rc das fêmeas foi provocado possivelmente pelo maior desenvolvimento de seus órgãos reprodutivos, o que não foi observado, em mesma intensidade, neste experimento.

O uso das diferentes rações não influenciou ( $\mathrm{P}>0,05)$ o peso das gônadas (Wg) das rãs (Tabela 3 ). Como era esperado, pelas diferenças anatômicas, o Wg das fêmeas foi maior $(\mathrm{P}<0,01)$ quando comparado aos machos. O mesmo ocorreu para o índice gonadossomático (IGS), que foi maior nas fêmeas e menor nos machos. O uso de diferentes rações não influenciou $(\mathrm{P}>0,05)$ o IGS.

As diferenças de IGS e Wg entre machos e fêmeas foi considerada pequena, se comparada a valores de animais com maior idade, conforme registrado por COSTA (1992) que o IGS para machos variou de $0,038 \%$ a $0,100 \%$ e, para fêmeas de $1,36 \%$ a 12,04\%, RIBEIRO FILHO (1999) encontrou IGS de $0,094 \%$ para machos e 2,925\% para fêmeas e RAMOS (2000) que encontrou médias de 0,1\% para machos e 13,6\% para fêmeas. Com animais de idade mais avançada, é esperado um maior desenvolvimento do aparelho reprodutivo das fêmeas, provocando maior diferença entre machos e fêmeas, visto que ovários e ovidutos atingem pesos maiores, quando comparados aos testículos. Portanto, ficou demonstrado que os animais ainda estavam no início do desenvolvimento de seus órgãos reprodutivos. Desta forma, se a opção for pelo aproveitamento das gônadas de fêmeas, será necessário um maior tempo de recria (acima de 84 dias) para o amadurecimento sexual dos animais com conseqüente maior peso de gônadas no abate, sendo que esse procedimento ainda necessita de comprovação científica e de estabelecimento dos limites de custo benefício.

As rãs alimentadas com as rações R1 e R4 obtiveram maiores médias $(\mathrm{P}<0,05)$ para peso de fígado (Wh), em relação às demais (Tabela 3 ). Não foi encontrada diferença $(\mathrm{P}>0,05)$ no Wh entre machos 
Tabela 3 - Efeito do tipo de ração e do sexo sobre o peso de carcaça (Wc), peso de gônadas (Wg), peso de fígado (Wh), peso de corpo gorduroso $(\mathrm{Wl})$, peso de pele $(\mathrm{Wp})$, peso de descartes $(\mathrm{Wd})$, rendimento de carcaça $(\mathrm{Rc})$, índice gonadossomático (IGS), índice hepatossomático (IHS), índice lipossomático (ILS), relação pele-peso vivo [R(Wp/Wt)], relação descartes-peso vivo [R(Wd/Wt)], em função das diferentes rações e sexos, após 56 dias de recria de rã-touro

\begin{tabular}{|c|c|c|c|c|c|c|c|c|c|c|c|c|}
\hline Tratamentos & Wc (g) & Wg(g) & Wh(g) & Wl (g) & Wp (g) & Wd (g) & Rc (\%) & IGS (\%) & IHS (\%) & ILS (\%) & $\mathrm{R}(\mathrm{Wp} / \mathrm{Wt})(\%)$ & $\mathrm{R}(\mathrm{Wd} / \mathrm{Wt})(\%)$ \\
\hline \multicolumn{13}{|l|}{ Rações $^{1}$} \\
\hline $\mathrm{R} 1$ & $123,08 a$ & $0,99 a$ & $10,16 \mathrm{a}$ & $12,57 b$ & $21,80 \mathrm{a}$ & $55,08 a$ & $55,04 a$ & 0,44 & $4,49 a$ & $5,61 \mathrm{~b}$ & 9,75 & $24,67 \mathrm{bc}$ \\
\hline R2 & $100,08 c$ & $0,58 a$ & $7,66 \mathrm{~b}$ & $8,45 c$ & $18,40 \mathrm{~b}$ & $48,38 b$ & $54,52 \mathrm{a}$ & 0,33 & 4,18ab & $4,63 c$ & 10,02 & 26,33ab \\
\hline R3 & 80,99d & $0,41 \mathrm{a}$ & $6,57 b$ & $9,63 c$ & $14,90 \mathrm{c}$ & $41,39 c$ & $52,72 b$ & 0,26 & 4,23ab & $6,14 b$ & 9,67 & $26,98 a$ \\
\hline R4 & $112,19 b$ & $0,96 a$ & $9,39 a$ & $15,56 a$ & $20,67 a b$ & $50,31 b$ & 53,83ab & 0,45 & $4,47 \mathrm{a}$ & $7,41 \mathrm{a}$ & 9,89 & $23,96 c$ \\
\hline R5 & $104,71 b c$ & $0,81 \mathrm{a}$ & $7,22 \mathrm{~b}$ & $12,65 b$ & 19,33ab & $48,46 b$ & $54,26 a$ & 0,42 & $3,65 b$ & $6,36 b$ & 9,94 & 25,39abc \\
\hline \multicolumn{13}{|l|}{ Sexos } \\
\hline Macho & 106,64 & $0,27 \mathrm{~B}$ & 7,81 & 11,58 & 19,66 & $50,48 \mathrm{~A}$ & 54,28 & $0,13 \mathrm{~B}$ & $3,93 \mathrm{~B}$ & 5,82 & $9,99 \mathrm{~A}$ & 25,85 \\
\hline Fêmea & 101,78 & $1,24 \mathrm{~A}$ & 8,59 & 11,97 & 18,38 & $46,96 B$ & 53,87 & $0,62 \mathrm{~A}$ & $4,48 \mathrm{~A}$ & 6,24 & $9,72 B$ & 25,08 \\
\hline \multicolumn{13}{|l|}{ Anova } \\
\hline Rações & $* *$ & $*$ & $* *$ & $* *$ & $* *$ & $* *$ & $* *$ & ns & $*$ & $* *$ & ns & $* *$ \\
\hline Sexos & ns & $* *$ & ns & ns & ns & $* *$ & ns & $* *$ & $* *$ & ns & $*$ & $*$ \\
\hline Rações X Sexos & ns & ns & ns & ns & ns & ns & ns & ns & ns & ns & ns & ns \\
\hline CV(\%) & 11,77 & 74,56 & 17,90 & 16,40 & 6,11 & 11,17 & 3,22 & 83,98 & 26,28 & 24,05 & 15,49 & 14,14 \\
\hline
\end{tabular}

a,b Médias de cada variável, seguidas de letras distintas nas colunas, diferem pelo teste $\mathrm{SNK}(\mathrm{P}<0,05)$.

A,B Médias, dentro de sexos, seguidas de letras distintas nas colunas, diferem pelo teste $\mathrm{F}(\mathrm{P}<0,05)$.

$* \mathrm{P}<0,05 ; * * \mathrm{P}<0,01$, ns = não significativo.

${ }^{1}$ R1= rãs na fase inicial; R2 = peixes onívoros na fase inicial; R3 = trutas na fase de crescimento; R4 = trutas na fase inicial; e R5 = peletizada.

e fêmeas, sendo a média dos machos de 7,81g e das fêmeas de 8,59g. Desta forma, se houver intenção de aproveitar esse órgão, deve-se optar pela ração R1 e $\mathrm{R} 4$, independente do sexo a ser criado.

Os valores médios de IHS das rãs alimentadas com as rações R1 e R4 foram maiores que os apresentados pelas rãs que receberam a R5, sendo que para rãs alimentadas com R2 e R3 o IHS não diferiu das demais (Tabela 3). As fêmeas tiveram maior IHS $(\mathrm{P}<0,05)$ em relação aos machos. LOUMBOURDIS \& KYRIAKOPOULOUSKLAVOUNOU (1991) demonstraram que o peso do fígado, corpo gorduroso e gônadas dos animais variam ao longo do ano com o período reprodutivo. COSTA (1992) encontrou IHS corrigido (não foi considerado o peso das gônadas) para machos variando de 3,45\% a 5,95\%, e para fêmeas de 2,49\% a 6,13\%, de acordo com a época do ano. STÉFANI (1996) mostrou resultados médios de 3,08\% IHS e, portanto menores que os encontrados neste trabalho, para animais recebendo rações com diferentes níveis de carboidratos e 30\% de PB. RIBEIRO FILHO (1999) encontrou maiores valores de IHS de machos e fêmeas (5,59\% e 5,78\%, respectivamente).

Considerando a possibilidade de aproveitamento do corpo gorduroso, foi observado que as rãs alimentadas com a R4 apresentaram um maior $(\mathrm{P}<0,05)$ peso de corpo gorduroso $(\mathrm{Wl})$, em relação às demais (Tabela 3 ). O sexo dos animais não influenciou ( $\mathrm{P}>0,05)$ o Wl, sendo a média dos machos de 11,58g e das fêmeas de 11,97g. Assim, se o produtor quiser aproveitar o corpo gorduroso de rã, para sua posterior comercialização, ele deverá optar pela ração R4 que proporcionou um maior estoque de gordura neste órgão, independentemente do sexo.

Os animais obtiveram maior $(\mathrm{P}<0,05)$ índice lipossomático (ILS), quando foi oferecida a ração R4. As rações R5, R3 e R1 proporcionaram menores médias em relação a R4, mas maiores quando comparadas a R2 (Tabela 3). O sexo dos animais não influenciou no ILS $(\mathrm{P}>0,05)$ dos animais. $\mathrm{O}$ valor médio de ILS dos machos foi de 5,82\% e das fêmeas de $6,24 \%$.

As diferenças entre ILS das rãs têm sido relacionadas com as atividades reprodutivas (LOUMBOURDIS \& KYRIAKOPOULOUSKLAVOUNOU, 1991), ou seja, uso de reservas de energia (corpo gorduroso) para a maturação do aparelho reprodutivo. Como os animais desse experimento ainda se encontravam imaturos, acredita-se que as diferenças encontradas para esse índice estão em função do tipo de ração utilizada. Para ajudar nesse estudo foi feita uma análise de correlações entre o ILS dos animais e os teores de extrato etéreo (EE) e energia bruta (EB) encontrados na ração (Tabela 4). Observa-se que as correlações obtidas com os machos têm valores (\%) maiores que os das fêmeas. As correlações foram positivas, ou

Ciência Rural, v. 35, n. 5, set-out, 2005. 
Tabela 4 - Coeficientes de correlação de Pearson entre índice lipossomático (ILS) e extrato etéreo (EE) e energia bruta (EB), para machos e fêmeas, na recria de rãtouro, em função do uso de diferentes rações ao final de 56 dias

\begin{tabular}{lll}
\hline \multirow{2}{*}{ Variáveis } & \multicolumn{2}{c}{ Correlações (\%) } \\
\cline { 2 - 3 } & Machos & Fêmeas \\
\hline ILS X EE & $62,12^{* *}$ & $53,80^{* *}$ \\
ILS X EB & $72,70^{* *}$ & $60,40^{* *}$ \\
\hline
\end{tabular}

** Significativo a $1 \%$ de probabilidade, pelo teste “t”.

seja, com o aumento dos níveis de EE e EB da ração houve aumento também de ILS.

Valores de ILS corrigido (por gônadas) para machos variando de 2,04\% a aproximadamente $4,80 \%$, e para fêmeas de $1,82 \%$ a 5,074\%, foram encontrados por COSTA (1992), de acordo com a época do ano. Já RIBEIRO FILHO (1999) encontrou ILS de 4,84\% nos machos e 4,92\% nas fêmeas. Índices para ILS com médias de 4,4\% para machos e de ILS corrigido (por gônadas) de 4,8\% para fêmeas, foram encontrados por RAMOS (2000). Esses autores usaram animais em diferentes estádios de maturação sexual.

Considerando o aproveitamento da pele, com o uso da ração R1, obtiveram-se as maiores médias $(\mathrm{P}<0,05)$ de peso de pele $(\mathrm{Wp})$, em relação à ração R2 e R3, a qual proporcionou a menor média, sendo formado um grupo intermediário pelas rações R5 e $\mathrm{R} 4$, estatisticamente iguais à R1 (Tabela 3 ). O sexo das rãs não influenciou $(\mathrm{P}>0,05)$ no $\mathrm{Wp}$, sendo a média dos machos de 19,66g e das fêmeas de 18,38g (Tabela $3)$. Se o produtor for aproveitar a pele dos animais, para posterior comercialização por peso, deverá usar a ração R1, por ter proporcionado maior peso para essa variável, independente do sexo a ser criado.

O uso das diferentes rações não influenciou $(\mathrm{P}>0,05)$ a relação pele/peso vivo $[\mathrm{R}(\mathrm{Wp} / \mathrm{Wt})]$. Os machos tiveram $(\mathrm{P}<0,05)$ maiores $\mathrm{R}(\mathrm{Wp} / \mathrm{Wt})$ em relação às fêmeas. Maiores índices de $\mathrm{R}(\mathrm{Wp} / \mathrm{Wt})$ de machos também foram encontrados por RAMOS (2000), com médias de 11,0\% e menores para fêmeas, com médias de 9,5\%. FONTANELLO et al. (1981) encontraram valores de $10,42 \%$ de $\mathrm{R}(\mathrm{Wp} / \mathrm{Wt})$ para machos e fêmeas. Valores somados de pata e pele de 16,17\% (machos) e 16,23\% (fêmeas) foram encontrados por RIBEIRO FILHO (1999). Ambos os autores utilizaram diferentes metodologias, peso e idades dos animais.

As rãs alimentadas com a ração $\mathrm{R} 1$ obtiveram as maiores médias $(\mathrm{P}<0,05)$ para peso de descartes (Wd) em relação às demais rações. A ração
R3, por sua vez, proporcionou a menor média de todas (Tabela 3). O sexo das rãs influenciou o $\mathrm{Wd}$ sendo que os machos tiveram $(\mathrm{P}<0,05)$ maiores médias, em relação às fêmeas. Constatou-se então, que se a intenção for aproveitar os descartes (pós-abate), devem-se usar machos e a ração R1.

Obteve-se maior relação descartes/peso vivo [R(Wd/Wt)], com o uso da ração R3, em relação à ração R1 e R4, estatisticamente iguais entre si. As rações R5 e R2 tiveram valores intermediários para esse parâmetro (Tabela 3). Essa relação não foi influenciada $(\mathrm{P}<0,05)$ pelo sexo da rã.

Valores de 16,5\% de índice viscerosomático para machos e fêmeas foram encontrados por FONTANELLO et al. (1981). Já RIBEIRO FILHO (1999) encontrou valores de cabeça e vísceras parciais somados de $19,68 \%$ para machos e $20,21 \%$ para fêmeas. No mesmo trabalho foram determinados valores para “vísceras totais” de 20,47\% para machos e 20,99\% para fêmeas. Valores de índices para vísceras brancas, cabeça e patas somados, de 23,3\% para machos e de $22,6 \%$ para fêmeas, foram determinados por RAMOS (2000). Ficou evidente a necessidade de padronização nos cálculos de parâmetros estudados, entre pesquisadores diferentes, para facilitar as comparações.

\section{CONCLUSÕES}

Se o volume de produção justificar o investimento em instalações para o beneficiamento de subprodutos, dentre as rações estudadas, a denominada para rãs é recomenda para o aproveitamento de fígado e descartes, e a aquela para trutas inicial, para aproveitamento de fígado e corpo gorduroso. Como atualmente o peso em carcaça é o que se privilegia em uma criação, recomenda-se também o uso das rações de rãs e de trutas inicial, que proporcionam valores satisfatórios de rendimento de carcaça e peso de carcaça. Quanto maior a quantidade de EE e EB na ração, maior é o Índice lipossomático dos animais. Após o abate dos animais, a utilização de um único sexo apenas influencia na maior quantidade de descartes, proporcionado pelos machos.

\section{REFERÊNCIAS}

AZEVEDO, A.G. Análise da carne de rã-touro gigante, realizada pelo Laboratório da Fábrica de Rações Anhangüera. In: ENCONTRO NACIONAL DE RANICULTURA - ENAR, 4., 1984, Goiânia, Go. Anais... Goiânia: Associação Goiana dos Criadores de Rãs, 1984 . p.217-219.

BARBALHO, O.J. de M. Exigência de proteína bruta de rã touro (Rana catesbeiana Shaw, 1802) na fase de

Ciência Rural, v.35 n. 5, set-out, 2005. 
terminação. 1991. 55f. Dissertação (Mestrado em Zootecnia) - Universidade Federal de Viçosa.

COSTA, C.L.S. Desenvolvimento do aparelho reprodutor e fatores associados ao ciclo reprodutivo da rã touro no Sistema Anfigranja. 1992. 98f. Dissertação (Mestrado em Zootecnia) - Universidade Federal de Viçosa.

FAUCONNEAU, B. et al. Growth and meat quality relations in carp. Aquaculture, Amsterdam, n.129, p.265-297, 1995.

FONTANELLO, D. et al. Avaliação e rendimento de carcaças de rãs-touro, Rana catesbeiana, provenientes de Juquitiba e destinadas a comercialização. Boletim do Instituto de Pesca, São Paulo, v.8, p.111-118, 1981.

JUDGE, M.D. et al. Principles of meat science. 2.ed. Ilust. Iowa: Kendal/Hunt Publishing, 1989. 351p.

LIMA, S.L.; AGOSTINHO, C.A. “Anfigranja”: Sistema de Criação intensiva de rãs. Encontro Nacional de Ranicultura ENAR 5, 1986, Porto Alegre, RS. In: ENCONTRO NACIONAL DE RANICULTURA - ENAR, 6., 1988, Rio de Janeiro. Coletânea... Rio de Janeiro: Associação dos Ranicultores do Estado do Rio de Janeiro - ARERJ, 1988. p.15-27.

LIMA, S.L.; AGOSTINHO, C.A. A tecnologia de criação de rãs. Viçosa: UFV, 1992. 168p.

LIMA, S.L. et al. Ranicultura: análise da cadeia produtiva. Viçosa: Folha de Viçosa, 1999. 172p.

LOUMBOURDIS, N.S.; KYRIAKOPOLOU-SKALAVOUNOU, P. Reproductive and lipid cycles in the male frog Rana Ridibunda in northern Greece. Comparative Biochemistry and Physiology, Oxford, v.99A, n.4, p.577-583, 1991.

MOURA, O.M. Efeito de métodos de insensibilização e sangria sobre características de qualidade da carne de rã-touro e perfil das indústrias de abate. 2000 . $208 \mathrm{f}$. Tese (Doutorado em Ciência e Tecnologia de Alimentos) Universidade Federal de Viçosa.
RAMOS, E.M. et al. Perfil de desenvolvimento e evolução do rendimento em carcaça de rãs-touro (Rana catesbeiana, Shaw 1802). In: CONGRESSO BRASILEIRO DE CIÊNCIA E TECNOLOGIA DE ALIMENTOS, 16., 1998, Rio de Janeiro. Anais... Rio de Janeiro: SBCTA, 1998. V.1, p.338-341.

RAMOS, E.M. Características Alométricas e químicas de rã touro (Rana catesbeiana Shaw, 1802). 2000. $103 \mathrm{f}$. Dissertação (Mestrado em Ciência e Tecnologia de Alimentos) - Universidade Federal de Viçosa.

RIBEIRO FILHO, O. P. Desempenho e avaliação de carcaça de rã-touro (Rana catesbeiana Shaw, 1802) criada em cativeiro com diferentes níveis de energia metabolizável na ração. 1999. 94 p. (Mestrado em Zootecnia) - Universidade Federal de Viçosa, Viçosa, MG.

RODRIGUES, R.L. et al. Avaliação bacteriológica de carne de rã (Leptodactylus $s p$ ) congelada, comercializada em Niterói, RJ. Higiene Alimentar, São Paulo, v.8, n.31, p.19-24, 1994.

SAEG - Sistemas de análises estatísticas (v.8.0). Viçosa: Universidade Federal de Viçosa, 2001.

SILVA, D. J. da. Análise de alimentos: métodos químicos e biológicos. Viçosa: Universidade Federal de Viçosa, 1981. 166p.

SILVA, N.R.; OLIVEIRA, L.A. Ocorrência de Salmonella na carne de rã (Rana catesbeiana, Shaw - 1803). Higiene Alimentar, São Paulo, v.8, n.31, p.36-40, 1994.

SILVA, D.L. Mercado de rãs no Brasil. In: INTERNATIONAL MEETING ON FROG RESEARCH AND TECHLOLOGY, 1; ENCONTRO NACIONAL DE RANICULTURA, 8., 1995, Viçosa. Anais... Viçosa: UFV, 1995. V.2, p.91.

STÉFANI, M.V. Metabolismo e crescimento da rã-touro (Rana catesbeiana Shaw, 1802) alimentada com níveis crescentes de carboidratos. 1996. 92f. Tese (Doutorado em Aqüicultura) - Universidade Estadual Paulista, Campus de Jaboticabal, SP. 